Polish Journal of Microbiology

2012, Vol. 61, No 1, 23-32

ORIGINAL PAPER

\title{
Characterization of Mutations Causing Rifampicin and Isoniazid Resistance of Mycobacterium tuberculosis in Syria
}

\author{
AMMAR MADANIA ${ }^{1 \star}$, MAYA HABOUS ${ }^{2}$, HANA ZARZOUR ${ }^{1}$, IFAD GHOURY ${ }^{1}$ and BAREA HEBBO ${ }^{2}$ \\ ${ }^{1}$ Department of Radiation Medicine, Atomic Energy Commission, P.O. 6091, Damascus, Syria \\ ${ }^{2}$ Reference TB Laboratory, Ibn-Al-Nafis Hospital, Ministry of Health, Damascus, Syria
}

Received 5 July 2011, revised 6 December 2011, accepted 12 December 2011

\begin{abstract}
In order to characterize mutations causing rifampicin and isoniazid resistance of M. tuberculosis in Syria, 69 rifampicin resistant (Rifr) and 72 isoniazid resistant $\left(\mathrm{Inh}^{\mathrm{r}}\right)$ isolates were screened for point mutations in hot spots of the rpoB, kat $G$ and inhA genes by DNA sequencing and real time PCR. Of 69 Rifr $^{r}$ isolates, $62(90 \%)$ had mutations in the rifampin resistance determining region (RRDR) of the $r p o B$ gene, with codons $531(61 \%), 526(13 \%)$, and $516(8.7 \%)$ being the most commonly mutated. We found two new mutations (Asp516Thr and Ser531Gly) described for the first time in the rpoB-RRDR in association with rifampicin resistance. Only one mutation (Ile572Phe) was found outside the rpoB-RRDR. Of $72 \mathrm{Inh}^{\mathrm{r}}$ strains, 30 (41.6\%) had a mutation in kat $G^{\text {codon } 315}$ (with Ser315Thr being the predominant alteration), and $23(32 \%)$ harbored the $i n h A^{-15 C \rightarrow T}$ mutation. While the general pattern of $r p o B$-RRDR and kat $G$ mutations reflected those found worldwide, the prevalence of the $i n h A^{-15 C \rightarrow T}$ mutation was above the value found in most other countries, emphasizing the great importance of testing the $i n h A^{-15 C \rightarrow T}$ mutation for prediction of isoniazid resistance in Syria. Sensitivity of a rapid test using real time PCR and 3'-Minor groove binder (MGB) probes in detecting Rifr and $\mathrm{Inh}^{\mathrm{r}}$ isolates was $90 \%$ and $69.4 \%$, respectively. This demonstrates that a small set of MGB-probes can be used in real time PCR in order to detect most mutations causing resistance to rifampicin and isoniazid.
\end{abstract}

Ke y words: M. tuberculosis, MDR, rpoB, katG, inhA, mutations, MGB-probes

\section{Introduction}

Every year more than 2 million people die from tuberculosis (TB) and about 9 million new TB cases emerge throughout the world (World Health Organization, 2005; Dye, 2006). In Syria, TB is still a public health threat with about 4000 new TB cases per year. After positive diagnosis, TB patients are treated with a quadruple antibiotic therapy including rifampicin (RIF) and isoniazid (INH). Although highly potent against sensitive TB strains, these drugs are ineffective in treating multidrug-resistant (MDR) M. tuberculosis strains (defined by their simultaneous resistance to at least RIF and INH). Ineffective chemotherapy increases the risk of TB transmission and unnecessarily exposes the patient to annoying side effects without any improvement. Therefore, rapid and sensitive testing for resistance to first line antibiotics (RIF and INH being the most important) is crucial in choosing drugs when starting therapy (World Health Organization, 2010).

M. tuberculosis can become drug resistant by acquiring mutations in genes encoding drug tar- gets or drug-converting enzymes. Mutations in the $\beta$ subunit of RNA polymerase, encoded by the $r p o B$ gene, are the main cause of resistance to RIF. Previous studies showed that more than $90 \%$ of the resistant strains harbor mutations within an 81-bp hot-spot region (codons 508-533) of the rpoB gene, termed RIF resistance determining region (RRDR) (Telenti et al., 1997). In contrast to RIF resistance, INH resistance is caused by a more complex genetic system that involves several genes (Slayden and Barry, 2000). Nevertheless, about half of Inh ${ }^{\mathrm{r}} \mathrm{TB}$ strains studied around the world have been shown to harbor mutations either in codon 315 of the kat $G$ gene (coding for catalaseperoxidase), and/or at position -15 of the promoter of the InhA gene (coding for enoyl-ACP-reductase, an enzyme involved in mycolic acid biosynthesis) (Ramaswamy et al., 2003; Zhang and Telenti, 2000). Although the absence of $r p o B$ and $k a t G / I n h A$ mutations does not mean drug sensitivity, the presence of such mutations indicates that the mutant bacilli are Rif ${ }^{\mathrm{r}}$ and/ or $\operatorname{Inh}^{\mathrm{r}}$ (positive predictive value $=100 \%$ ). Therefore, it is possible to predict the resistance of a M. tuberculosis

* Corresponding author: A. Madania, Section of Medical Biology, Department of Radiation Medicine, Atomic Energy Commission, P.O. 6091, Damascus, Syria; phone: +963-11-2132580; fax: +963-11-6112289; e-mail: ascientific@aec.org.sy 
strain to these drugs simply by detecting such mutations. Although bacterial culture remains the "gold standard" in drug susceptibility testing, this method is slow and requires at least 2 weeks to obtain results (Narvaiz et al., 1998). Therefore, it is useful to test for $r p o B$ and $k a t G / I n h A$ mutations in order to rapidly predict RIF and INH resistance and guide therapy at an early stage.

Several molecular methods have been developed to evaluate the $r p o B$ gene for RIF resistance mutations, including DNA sequencing, line probe assay, SSCP (single strand conformation polymorphism), ARMS (amplification refractory mutation system) and realtime PCR using fluorescent Taqman probes (García de Viedma, 2003). Since there are no previous studies assessing mutations that cause RIF and INH resistance in Syria, it is difficult to choose the most efficient and cost effective molecular method to detect such mutations in order to guide therapy for Syrian patients.

In this study, we have characterized $r p o B$ RRDRmutations in $\operatorname{Rif}^{\mathrm{r}} M$. tuberculosis strains isolated from Syrian TB patients and further screened for $k a t G^{\text {codon } 315}$ and $i n h A^{-15}$ mutations in $\operatorname{Inh}^{\mathrm{r}}$ isolates. In addition, we have evaluated a rapid real-time PCR method which could be used as first-line test to detect the most frequent mutations causing RIF and INH resistance among M. tuberculosis strains.

\section{Experimental}

\section{Materials and Methods}

Clinical isolates and bacterial culture. 160 M. tuberculosis bacterial strains were cultured from sputum specimens of 160 different, unrelated pulmonary Syrian TB patients referred to our laboratory during a 3 years period (June 2007 - June 2010). About 30\% of these patients were referred to us for TB diagnosis. All remaining patients had a history of failing chemotherapy and were referred to us for drug resistance assess- ment. M. tuberculosis bacterial strains were cultured following conventional methods (Narvaiz et al., 1998). Briefly, sputum specimens were decontaminated with $4 \% \mathrm{NaOH}$ and cultured on Lőwenstein solid medium by incubation at $37 \mathrm{C}^{\circ}$ for 3-10 weeks, until M. tuberculosis colonies appeared on the medium surface. Resistance to RIF and INH was tested by culturing bacterial suspensions (0.5 McFarland) on Löwenstein solid medium containing rifampicin $(40 \mu \mathrm{g} / \mathrm{ml})$ or isoniazid $(0.2 \mu \mathrm{g} / \mathrm{ml})$. A M. tuberculosis isolate was considered as drug resistant only when the number of colonies emerging on drug containing medium was at least $1 \%$ of the number of colonies emerging on drug free medium (Narvaiz et al., 1998).

Isolation of genomic DNA from M.tuberculosis colonies. gDNA was isolated from bacilli following standard phenol/chloroform extraction. Briefly, a $1 \mathrm{~mm}$ bacterial colony was resuspended in $500 \mu \mathrm{l}$ $\mathrm{H}_{2} \mathrm{O}$ and cells were lysed by adding $50 \mu \mathrm{l} 10 \%$ SDS and $15 \mu \mathrm{l}$ Proteinase $\mathrm{K}(10 \mathrm{mg} / \mathrm{ml})$ and incubating for $1 \mathrm{~h}$ at $50 \mathrm{C}^{\circ}$ under shaking. gDNA was extracted once with phenol and 3 times with chloroform and precipitated with ethanol, washed with 75\% ethanol, air dried and dissolved in $200 \mu \mathrm{l}$ water. gDNA yields varied between 10 and $100 \mathrm{ng} / \mu \mathrm{l}$.

PCR amplification and sequencing of genomic rpoB-RRDR and $k a t G$ codon 315 regions. M. tuberculosis rpoB and kat $G$ reference sequences (GenBank accession L27989 and X68081, respectively) were used to design two PCR primer pairs (rpoB-13/rpoB-36 and katG-1/katG-2, see Table I). The first pair flanked the RRDR of the $r p o B$ gene and amplified a 641 bp PCR fragment, while the second pair flanked codon 315 of the kat $G$ gene and amplified a 447 bp PCR fragment. Each PCR reaction ( $25 \mu$ final volume) contained following components (final concentrations): buffer $(1 \times)$, $\mathrm{MgCl}_{2}$ (3 mM), dNTPs (200 $\mu \mathrm{M}$ each), DMSO (5\%), primer pair (300 nM each), Taq polymerase (1 unit GoTaq, Promega) and gDNA (30-100 ng). PCR reactions were run in an Eppendorf thermocycler with

Table I

Primers used in this study

\begin{tabular}{|c|c|c|}
\hline Primer & Sequence $\left(5^{\prime} \rightarrow 3^{\prime}\right)$ & PCR product \\
\hline rpoB-13 & CCTGGCCCGCGTCGGTCGCT & \multirow{2}{*}{$641 \mathrm{bp}(r p o B-\mathrm{RRDR})$} \\
\hline rpoB-36 & CGACCACCTTGCGGTACGGCGT & \\
\hline rpoB-1 & CAAAACCAGATCCGGGTCG & \multirow{3}{*}{$300 \mathrm{bp}(r p o B-\mathrm{RRDR})$} \\
\hline rpoB-2 & TCGGGCACATCCGGCCGTAG & \\
\hline rpoB-seq & ACCGACGACATCGACCACTT & \\
\hline katG-1 & AGCCCGATGAGGTCTATTGGGGC & \multirow{3}{*}{447 bp $\left(k a t G^{\text {codon315 }}\right)$} \\
\hline katG-2 & ACTCGTAGCCGTACAGGATCTCGAGG & \\
\hline katG-seq & GCAGATGGGGCTGATCTACG & \\
\hline inhA-1 & CACCCGCAGCCAGGGCCTCG & \multirow{2}{*}{$265 \mathrm{bp}\left(i n h A^{-15}\right)$} \\
\hline inhA-2 & CGATCCCCCGGTTTCCTCCGG & \\
\hline
\end{tabular}




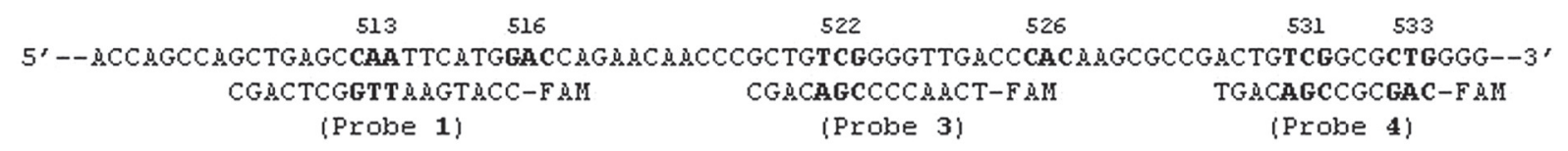

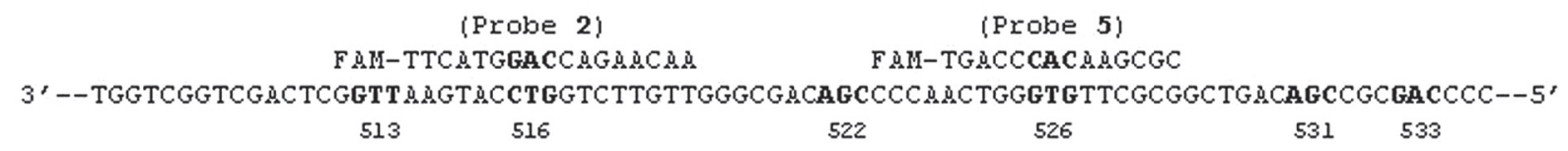

Fig. 1. 5'-FAM-labeled MGB-probes (minor groove binding) used for detection of mutations in the rifampin resistance determining region of the $r p o B$ gene ( $r p o B$-RRDR) of $M$. tuberculosis.

All probes have an MGB moiety at their 3' end (not shown). Shown are the two antiparallel strands of the wild type rpoB-RRDR genomic sequence. Codon number (according to the numbering of $r p o B$ of E. coli) is indicated above (or beneath) each codon frequently mutated in this region and leading to rifampicin resistance.

the following cycling conditions: initial denaturation $95 \mathrm{C}^{\circ}$ for $3 \mathrm{~min}$, then 32 cycles of $94 \mathrm{C}^{\circ}$ for $20 \mathrm{sec}$, $60 \mathrm{C}^{\circ}$ for $20 \mathrm{sec}$ and $72 \mathrm{C}^{\circ}$ for $50 \mathrm{sec}$ (final elongation cycle at $72 \mathrm{C}^{\circ}$ for $3 \mathrm{~min}$ ). After electrophoresis in a $2 \%$ agarose gel containing ethidium bromide, the amplified products were visualized and photographed using a UV-transilluminator.

PCR products were sequenced only in the forward direction using either primer rpoB-seq (situated $122 \mathrm{bp}$ upstream of the RRDR of the $r p o B$ gene) or katG-seq (situated $254 \mathrm{bp}$ upstream of codon 315 of the katG gene) (Table I). Sequencing reactions were set up using BigDye Terminator chemistry (Applied Biosystems, version 3.1) following the manufacturer's instructions. Fluorescent elongation/termination products were separated by high voltage capillary electrophoresis on an ABI 310 instrument (Applied Biosystems). Raw data were analyzed using the Data Analysis software (Applied Biosystems, version 3.1). Each peak in the electropherograms was checked visually by two different persons in order to verify correct base calling. Sequences were aligned to the reference "wild type" sequence (Genbank L27989 and X68081) and mutations were highlighted using the SeqScape software (Applied Biosystems, version 2.5).

Triplex-PCR. In order to detect point mutations in the rpoB-RRDR, $k a t G^{\text {codon } 315}$ and $i n h A^{-15}$ by real time PCR, rpoB, kat $G$ and $i n h A$ genomic regions were first co-amplified in one single tube. Each triplex
PCR reaction $(25 \mu$ final volume) contained following components (final concentrations): buffer $(1 \times)$, $\mathrm{MgCl}_{2}(3.5 \mathrm{mM})$, dNTPs (200 $\mu \mathrm{M}$ each), DMSO (5\%), primer pair rpoB-13/rpoB-36 (300 $\mathrm{nM}$ each), primer pair katG-1/katG-2 (300 nM each), primer pair inhA-1/ inhA-2 (500 nM each), Taq polymerase (1 unit, Hotstart GoTaq, Promega), and gDNA (30-100 ng). PCR cycling conditions were the same as in the previous section. After electrophoresis in a 2\% agarose gel containing ethidium bromide, the presence of three bands of the correct sizes was checked for each reaction: $r p o B$ (641 bp), katG (447 bp) and inhA (265 bp, containing position -15 of the mabA-inhA promoter). Triplex-PCR products were first diluted 1:50 in water and then used as templates in all subsequent real-time PCR reactions.

Taqman-probes. We used five MGB-probes (minor groove binding probes, Wada et al., 2004), covering most frequently mutated codons in the RRDR of the $r p o B$ gene (Fig. 1), in addition to one MGB-probe covering codon 315 of the kat $G$ gene, and two allele specific MGB-probes covering position -15 of the mabAinhA promoter (Table II). All probes were FAM-labeled at their 5' ends (purchased from Applied Biosystems).

Real-time PCR. Each real-time PCR experiment included at least one RIF and INH sensitive M. tuberculosis isolate as "wild type" control. For each M. tuberculosis isolate tested, a total of eight real-time PCR tubes (A-H) were set up ( $20 \mu$ l final volume). All tubes contained the following common components (final

Table II

3'-Minor groove binder-DNA probes (MGB-probes) used in this study

\begin{tabular}{|l|l|l|}
\hline \multicolumn{1}{|c|}{ Probe name } & \multicolumn{1}{|c|}{ Sequence $\left(5^{\prime} \rightarrow 3^{\prime}\right)$} & \multicolumn{1}{c|}{ DNA target } \\
\hline rpoB-Probe 1 & FAM-CCATGAATTGGCTCAGC-MGB & $r p o B$ codons $511 \ldots 515$ \\
\hline rpoB-Probe 2 & FAM-TTCATGGACCAGAACAA-MGB & $r p o B$ codons $514 \ldots 518$ \\
\hline rpoB-Probe 3 & FAM-TCAACCCCGACAGC-MGB & $r p o B$ codons $521 \ldots 524$ \\
\hline rpoB-Probe 4 & FAM-CAGCGCCGACAGT-MGB & $r p o B$ codons $529 \ldots 533$ \\
\hline rpoB-Probe 5 & FAM-TGACCCACAAGCGC-MGB & $r p o B$ codons $524 \ldots 528$ \\
\hline katG-Probe & FAM-CACCAGCGGCATC-MGB & $k a t G$ codons $314 \ldots 317$ \\
\hline inhA-Probe 1 & FAM-ACCTATCGTCTCGCCG-MGB & inhA promoter $-8 \ldots-23(\mathrm{WT})$ \\
\hline inhA-Probe 2 & FAM-ACCTATCATCTCGCCG-MGB & inhA promoter $-8 \ldots-23(-15 \mathrm{C} \rightarrow$ T mutation $)$ \\
\hline
\end{tabular}


Table III

\begin{tabular}{|l|c|c|c|c|c|c|c|c|}
\hline & Tube A & Tube B & Tube C & Tube D & Tube E & Tube F & Tube G & Tube H \\
\hline Probes & $\begin{array}{c}\text { rpoB-Probe 1 } \\
(120 \mathrm{nM})\end{array}$ & $\begin{array}{c}\text { rpoB-Probe 2 } \\
(120 \mathrm{nM})\end{array}$ & $\begin{array}{c}\text { rpoB-Probe 3 } \\
(100 \mathrm{nM})\end{array}$ & $\begin{array}{c}\text { rpoB-Probe 4 } \\
(400 \mathrm{nM})\end{array}$ & $\begin{array}{c}\text { rpoB-Probe 5 } \\
(100 \mathrm{nM})\end{array}$ & $\begin{array}{c}\text { katG-Probe } \\
(100 \mathrm{nM})\end{array}$ & $\begin{array}{c}\text { inhA -Probe 1 } \\
(100 \mathrm{nM})\end{array}$ & $\begin{array}{c}\text { inhA -Probe 2 } \\
(100 \mathrm{nM})\end{array}$ \\
\hline $\begin{array}{l}\text { Primers } \\
\text { 300 nM } \\
\text { each }\end{array}$ & \multicolumn{5}{|c}{$\begin{array}{c}\text { rpoB-1 } \\
\text { rpoB-2 }\end{array}$} & $\begin{array}{c}\text { katG-1 } \\
\text { inhA-1 } \\
\text { katG-2 }\end{array}$ & + \\
inhA-2 \\
\hline
\end{tabular}

Primers and MGB-probes added to each real-time PCR reaction (total of 8 tubes, A-H). The concentration of each probe is indicated in parentheses.

concentrations): buffer $(1 \times), \mathrm{MgCl}_{2}(4 \mathrm{mM})$, dNTPs (200 $\mu \mathrm{M}$ each), DMSO (5\%), Taq polymerase (1 unit GoTaq, Promega), $4 \mu$ l diluted triplex-PCR products. Primers and probes were added to each tube according to Table III.

Real-time PCR was performed using a Quantica instrument (Techne, England) with the following cycling conditions ( 35 cycles): $94 \mathrm{C}^{\circ}$ for $15 \mathrm{sec}, 60 \mathrm{C}^{\circ}$ for $1 \mathrm{~min}$ (annealing and extension in one step). Fluorescence acquisition was performed in the FAM-channel at the end of each cycle. Data were analyzed using Quansoft software (Techne). For each reaction tube, amplification curves were plotted against cycle number. The shape of each amplification curve was compared to the shape of the corresponding curve of the "wild type" control.

The presence of a mutation was suspected if the amplification curve corresponding to a probe (compared to the "wild type" curve), did not show a typical sigmoid (exponential) shape, and had rather a flatten shape, with little or no fluorescence increase with increasing cycle number. Suspected mutations were retested to confirm results.

\section{Results}

RIF and INH susceptibility test. Of the total 160 M. tuberculosis tested isolates, 69 (43\%) were Rifr and 91 were Rifs, whereas $72(45 \%)$ isolates were $\operatorname{Inh}^{\mathrm{r}}$ and 88 were Inhs. $61(38 \%)$ isolates were resistant to both RIF and INH (MDR), whereas 80 (50\%) were sensitive to both drugs. 8 (5\%) were RIF monoresistant isolates, and $11(7 \%)$ were INH monoresistant isolates.

Point mutations in the rpoB-RRDR revealed by DNA sequencing. For each of the 69 Rifr $^{\mathrm{r}}$ strains found in this study, a PCR fragment containing the RRDR (codons 508-534) of the rpoB gene was amplified and PCR products were sequenced in the forward direction. Reliable base calling started at codon 496, and reading was stopped at codon 663 (excluding the region of the reverse PCR primer). Sequencing revealed mutations in $63(91 \%)$ strains, whereas 6 strains did not show any mutations in the sequenced region. Fig. 2 and Table IV show the exact nucleotide change(s) in each Rif ${ }^{\mathrm{r}}$ strain and the corresponding amino acid changes in the RNApolymerase $\beta$-subunit.

Mutant isolates with two amino acid changes (total 3)

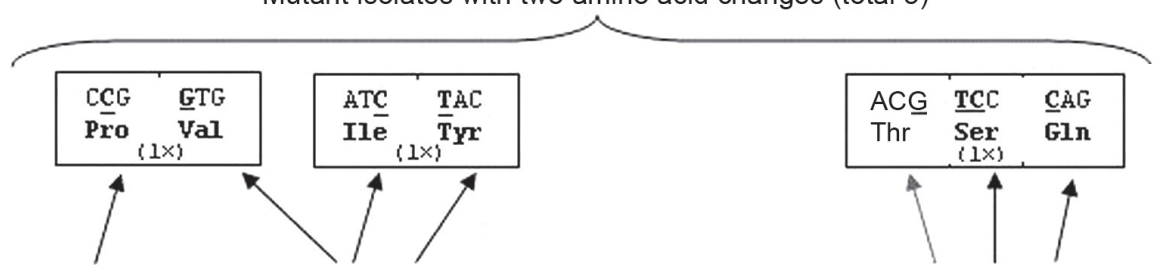

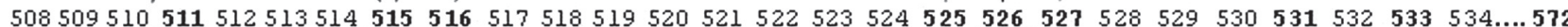
Thr Ser Gin Leu Ser Gln Phe Ret Asp Gln Asn Asn Pro Leu Ser Gly Leu Thr His LYs Ârg Arg Leu Ser Ala Leu GlY.... Tle ACC AGC CAG CTG AGC CAA TTC ATG GAC CAG AAC AAC CCG CTG TCG GGG TTG ACC CAC AAG CGC CGA CTG TCG GCG CTG GGG....ATC

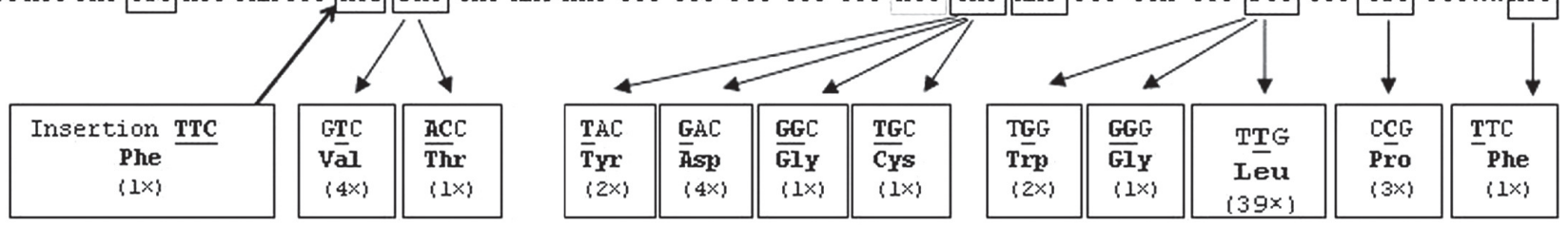

Mutant isolates with single amino acid change (total 60)

Fig. 2. $r p o B$ mutations found in rifampicin-resistant M. tuberculosis isolates studied in this work.

Middle panel: wild type sequence of the RRDR of the $r p o B$ gene. Codon number (according to the numbering of $r p o B$ of $E$. coli) and corresponding amino acid are indicated above each codon. Codons involved in mutations are boxed. Arrows indicate mutated codons. Bottom panel: mutant isolates with one single amino acid change. Each box includes the mutated codon and the corresponding changed amino acid (in parentheses: total number of isolates bearing the same mutation). Upper panel: mutant isolates with two amino acid changes (double mutants). Each box includes mutated codons and the corresponding changed amino acids. (RRDR = rifampicin resistance determining region). 
Table IV

\begin{tabular}{|c|c|c|c|c|}
\hline $\begin{array}{l}\text { Mutation in inh } A^{-15} \\
\text { (real-time PCR) }\end{array}$ & $\begin{array}{l}\text { Mutation in kat } G \\
\text { (DNA sequencing) }\end{array}$ & $\begin{array}{l}\text { Mutation in } r p o B \\
\text { (DNA sequencing) }\end{array}$ & $\begin{array}{c}\text { RIF / INH } \\
\text { susceptibility }\end{array}$ & $\begin{array}{c}\text { Number of isolates } \\
\text { (total 160) }\end{array}$ \\
\hline No mutations & S315T (A $\underline{\text { GC }} \rightarrow$ A $\underline{C} C)$ & L533P (CIGG $\rightarrow$ C $\underline{C} G)$ & $\mathrm{R} / \mathrm{R}$ & 3 \\
\hline $\operatorname{inh} A^{-15} \mathrm{C} \rightarrow \mathrm{T}$ & No mutations & S531L (TㅁG $\rightarrow$ TTG $)$ & $\mathrm{R} / \mathrm{R}$ & 14 \\
\hline No mutations & $\mathrm{S} 315 \mathrm{~T}(\mathrm{~A} \underline{\mathrm{G}} \mathrm{C} \rightarrow \mathrm{A} \underline{\mathrm{CC}})$ & S531L $(\mathrm{T} \underline{\mathrm{C} G} \rightarrow \mathrm{TT} G)$ & $\mathrm{R} / \mathrm{R}$ & 13 \\
\hline No mutations & S315N (AGC $\rightarrow$ A $\underline{A} C)$ & S531L (TGG $\rightarrow$ TTG $)$ & $\mathrm{R} / \mathrm{R}$ & 1 \\
\hline No mutations & No mutations & S531L (TㅁG $\rightarrow$ TTG $)$ & $\mathrm{R} / \mathrm{R}$ & 7 \\
\hline No mutations & $\mathrm{ND}$ & S531L (TㅁG $\rightarrow$ TTG $)$ & $\mathrm{R} / \mathrm{S}$ & 4 \\
\hline No mutations & $\mathrm{ND}$ & S531W (TㅁG $\rightarrow$ T $\underline{G G})$ & $\mathrm{R} / \mathrm{S}$ & 1 \\
\hline No mutations & No mutations & S531W (T́G $\rightarrow$ T $\underline{G} G)$ & $\mathrm{R} / \mathrm{R}$ & 1 \\
\hline No mutations & ND & S531G (TCG $\rightarrow \underline{\text { GGG})}$ & $\mathrm{R} / \mathrm{S}$ & 1 \\
\hline$i n h A^{-15} \mathbf{C} \rightarrow \mathbf{T}$ & No mutations & $\mathrm{H} 526 \mathrm{D}(\underline{\mathbf{C} A C} \rightarrow \underline{\mathbf{G}} \mathrm{AC})$ & $\mathrm{R} / \mathrm{R}$ & 2 \\
\hline No mutations & No mutations & $\mathrm{H} 526 \mathrm{D}(\underline{\mathbf{C}} A \mathrm{C} \rightarrow \underline{\mathrm{G}} A \mathrm{C})$ & $\mathrm{R} / \mathrm{R}$ & 2 \\
\hline No mutations & S315T (AGC $\rightarrow$ ACC $)$ & $\mathrm{H} 526 \mathrm{Y}(\underline{\mathbf{C}} A \mathrm{C} \rightarrow \underline{\mathbf{T}} A \mathrm{C})$ & $\mathrm{R} / \mathrm{R}$ & 2 \\
\hline No mutations & No mutations & $\mathrm{H} 526 \mathrm{C}(\underline{\mathrm{CAC}} \rightarrow \underline{\mathrm{TGC}})$ & $\mathrm{R} / \mathrm{R}$ & 1 \\
\hline No mutations & $\mathrm{S} 315 \mathrm{~T}(\mathrm{~A} \underline{\mathrm{G} C} \rightarrow \mathrm{A} \underline{\mathrm{C} C})$ & $\mathrm{H} 526 \mathrm{G}(\underline{\mathrm{CAC}} \rightarrow \underline{\mathrm{GGC}})$ & $\mathrm{R} / \mathrm{R}$ & 1 \\
\hline No mutations & S315T $(\mathrm{A} \underline{\mathbf{G}} \mathrm{C} \rightarrow \mathrm{A} \underline{\mathbf{C}} \mathrm{C})$ & 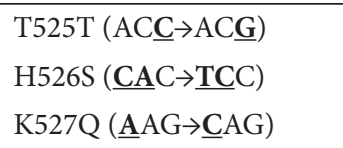 & $\mathrm{R} / \mathrm{R}$ & 1 \\
\hline$i n h A^{-15} \mathbf{C} \rightarrow \mathbf{T}$ & S315T (A $\underline{A} C \rightarrow A \underline{C} C)$ & 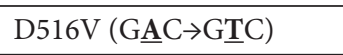 & $\mathrm{R} / \mathrm{R}$ & 3 \\
\hline No mutations & No mutations & $\mathrm{D} 516 \mathrm{~V}(\mathrm{G} \underline{\mathbf{A} C} \rightarrow \mathrm{G} \underline{\mathbf{T} C})$ & $\mathrm{R} / \mathrm{R}$ & 1 \\
\hline No mutations & No mutations & $\mathrm{D} 516 \mathrm{~T}(\underline{\mathbf{G A C}} \rightarrow \underline{\mathbf{A C C}})$ & $\mathrm{R} / \mathrm{R}$ & 1 \\
\hline No mutations & No mutations & $\begin{array}{l}\text { D516Y }(\underline{\text { GAC } \rightarrow \underline{T A C})} \\
\text { M515I (AT } \underline{\text { G }} \rightarrow \text { AT } \underline{\mathbf{C}})\end{array}$ & $\mathrm{R} / \mathrm{R}$ & 1 \\
\hline No mutations & $\mathrm{S} 315 \mathrm{~T}(\mathrm{~A} \underline{\mathbf{G} C} \rightarrow \mathrm{A} \underline{\mathbf{C} C})$ & $\begin{array}{l}\text { M515V }(\underline{\mathbf{A} T G} \rightarrow \underline{\mathrm{GTG}}) \\
\text { L511P }(\mathrm{C} \underline{\mathbf{T}} \rightarrow \mathrm{C} \underline{\mathbf{C} G})\end{array}$ & $\mathrm{R} / \mathrm{R}$ & 1 \\
\hline No mutations & S315T $(\mathrm{AGC} \rightarrow \mathrm{ACG})$ & 514 insertion F (Ins $\underline{\mathbf{T T C}})$ & $\mathrm{R} / \mathrm{R}$ & 1 \\
\hline No mutations & S315T (A $\underline{\text { GC }} \rightarrow$ A $\underline{C} C)$ & I572F $(\underline{\mathbf{A} T C} \rightarrow \underline{\mathbf{T} T C})$ & $\mathrm{R} / \mathrm{R}$ & 1 \\
\hline No mutations & No mutations & No mutations & $\mathrm{R} / \mathrm{R}$ & 3 \\
\hline No mutations & ND & No mutations & $\mathrm{R} / \mathrm{S}$ & 2 \\
\hline $\operatorname{inh} A^{-15} \mathrm{C} \rightarrow \mathrm{T}$ & No mutations & No mutations & $\mathrm{R} / \mathrm{R}$ & 1 \\
\hline No mutations & $\mathrm{S} 315 \mathrm{~T}(\mathrm{~A} \underline{\mathrm{G} C} \rightarrow \mathrm{A} \underline{\mathrm{CC}})$ & ND & $S / R$ & 2 \\
\hline No mutations & S315T (A $\underline{\text { GC }} \rightarrow$ ACG $)$ & ND & $\mathrm{S} / \mathrm{R}$ & 1 \\
\hline $\operatorname{inh} A^{-15} \mathbf{C} \rightarrow \mathbf{T}$ & No mutations & ND & $\mathrm{S} / \mathrm{R}$ & 3 \\
\hline No mutations & No mutations & ND & $\mathrm{S} / \mathrm{R}$ & 5 \\
\hline No mutations & $\mathrm{ND}$ & ND & $S / S$ & 80 \\
\hline
\end{tabular}

Summary of results of drug resistance testing and mutation detection in $r p o B, k a t G$ and $i n h A$ for a total of $160 \mathrm{M}$. tuberculosis isolates included in this study. $\mathrm{R}=$ resistant. $\mathrm{S}=$ sensitive. $\mathrm{ND}=$ not determined. Amino acids are written with the one-letter code. Exact mutations in the corresponding codon are indicated in parentheses.

Most frequently mutated was codon 531, where mutations were found in $42(61 \%)$ of Rif $^{r}$ strains. The remarkably most frequent mutation was 531-Tㅁ $\rightarrow$ T T G (Ser531Leu), which occurred in 39 (56.5\%) Rifr strains, whereas the mutation 531-TG $\rightarrow$ T $\underline{G}$ (Ser531Trp) occurred only in $2(2.9 \%)$ isolates. Interestingly, one RIF $^{\mathrm{r}}$ strain had a mutation at codon 531 that involved

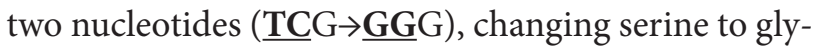
cine (Ser531Gly). This mutation has, to our knowledge, never been previously described.
Mutations at codon 526 in RIFr strains occurred quite frequently (13\%), mostly changing histidine to aspartate or tyrosine. Interestingly, we found one Rif ${ }^{r}$ strain with four consecutive mutated nucleotides, changing histidine 526 to serine and lysine 527 to glutamine (His526Ser+Lys527Gln double mutant, with a silent mutation at codon 525).

Mutations at codon 516 occurred less frequently (8.7\%), mostly changing aspartate to valine or tyrosine. We found one Rif ${ }^{\mathrm{r}}$ strain bearing a mutation at 


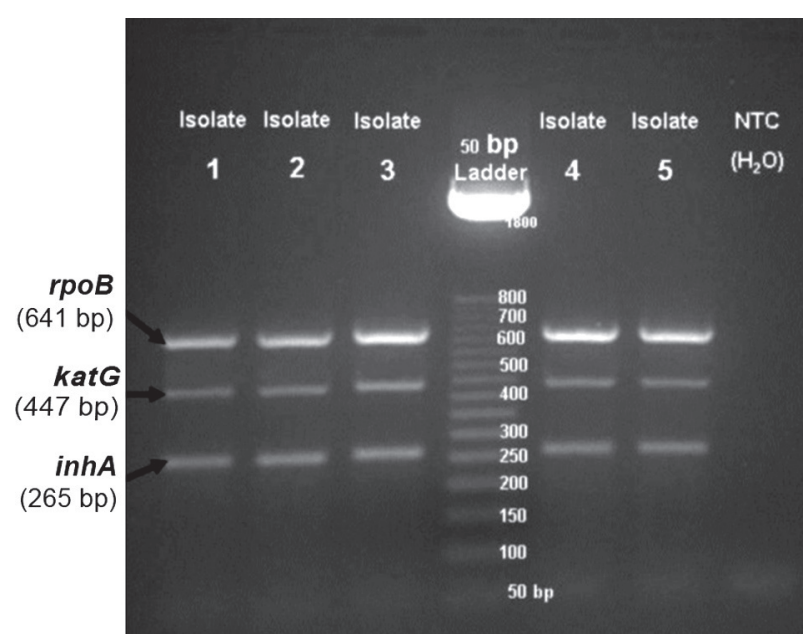

Fig. 3. Agarose gel electrophoresis of triplex-PCR reactions.

Shown are the products of triplex-PCR reactions for the amplification of $r p o B, k a t G$ and inh $A$ genomic regions of five different $M$. tuberculosis isolates plus a non-template control (NTC, negative control with $\mathrm{H}_{2} \mathrm{O}$ instead of gDNA). For each isolate, three PCR fragments are amplified and seen on the gel as three distinct bands (indicated by the arrows): $r p o B$ (641 bp, containing the RRDR), $k a t G$ ( $447 \mathrm{bp}$, containing codon 315 ) and inhA (265 bp, containing position - 15 of the mabA-inhA promoter).

codons 516 that involved two nucleotides $(\underline{\mathbf{G A C}} \rightarrow \underline{\mathbf{A C C}})$, changing aspartate to threonine (Asp516Thr). This mutation has also, to our knowledge, never been previously described.

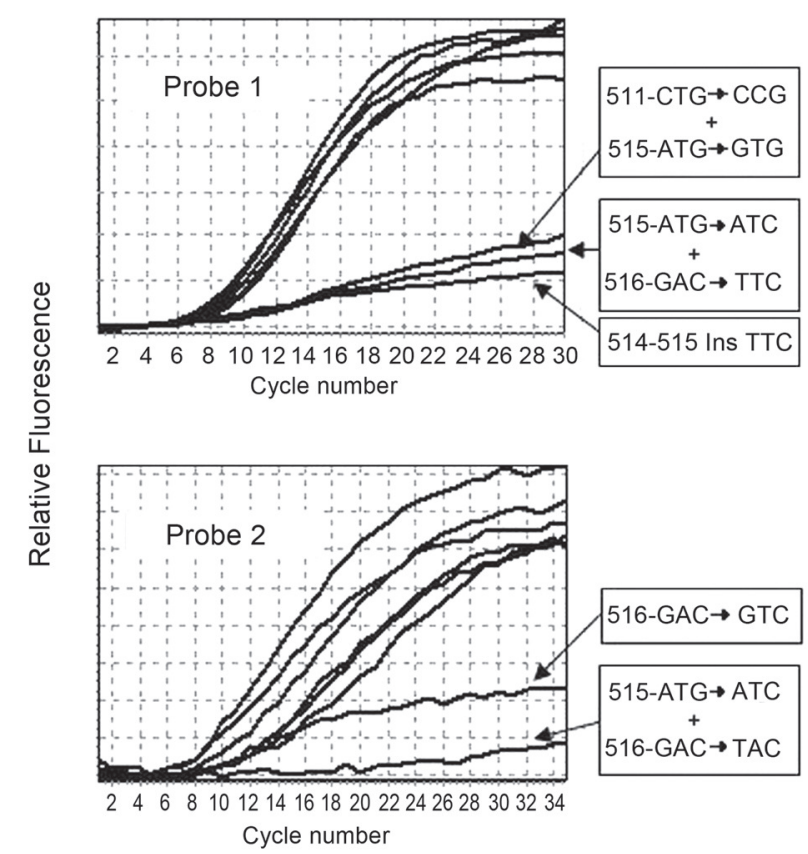

Finally, rare mutations occurred at codon 533 (4.3\%, Leu $\rightarrow$ Pro), codon 511 (1.5\%, Leu $\rightarrow$ Pro) and codon 515 (1.5\%, insertion of Phe). Interestingly, we found only one Rif ${ }^{\mathrm{r}}$ strain bearing a mutation outside the RRDR. This mutation occurred at codon $572(\underline{\mathrm{A} T C} \rightarrow \underline{\mathrm{T} T C})$ changing isoleucine to phenylalanine (Ile572Phe). Rifr $^{\mathrm{r}}$ isolates harboring this mutation were previously reported by only four other groups (Yuen et al., 1999; Bobadilla-del-Valle etal., 2001; Heep et al., 2001; McCammon et al., 2005).

Mutations at codon 315 of the $k a t G$ gene revealed by DNA sequencing. For each of the $72 \mathrm{Inh}^{\mathrm{r}}$ strains found in this study, a PCR fragment containing codon 315 of the kat $G$ gene was amplified and PCR products were sequenced in the forward direction. Reliable base calling started at codon 242, and reading was stopped at codon 333 (excluding the region of the reverse PCR primer). Sequencing revealed mutations in 30 (41.6\%) strains, whereas 42 strains did not show any mutations in the sequenced region. Mutations occurred exclusively at codon 315 . The most frequent mutation was A $\underline{\mathbf{G}} \rightarrow \mathrm{A} \underline{\mathrm{C} C}$ (27 out of 30 mutants, 90\%), changing serine to threonine (Ser315Thr). We found also two isolates bearing the mutation $\mathrm{A} \underline{\mathbf{G C}} \rightarrow \mathrm{ACG}$ with the same amino acid change. The mutation $\mathrm{A} \underline{\mathbf{G}} \rightarrow \mathrm{A} \underline{\mathrm{AC}}$ (Ser315Asn) was found only in one isolate.

Detection of point mutations in the rpoB-RRDR, $k a t G^{\text {codon315 }}$ and $i n h A^{-15}$ by real time PCR. For rapid
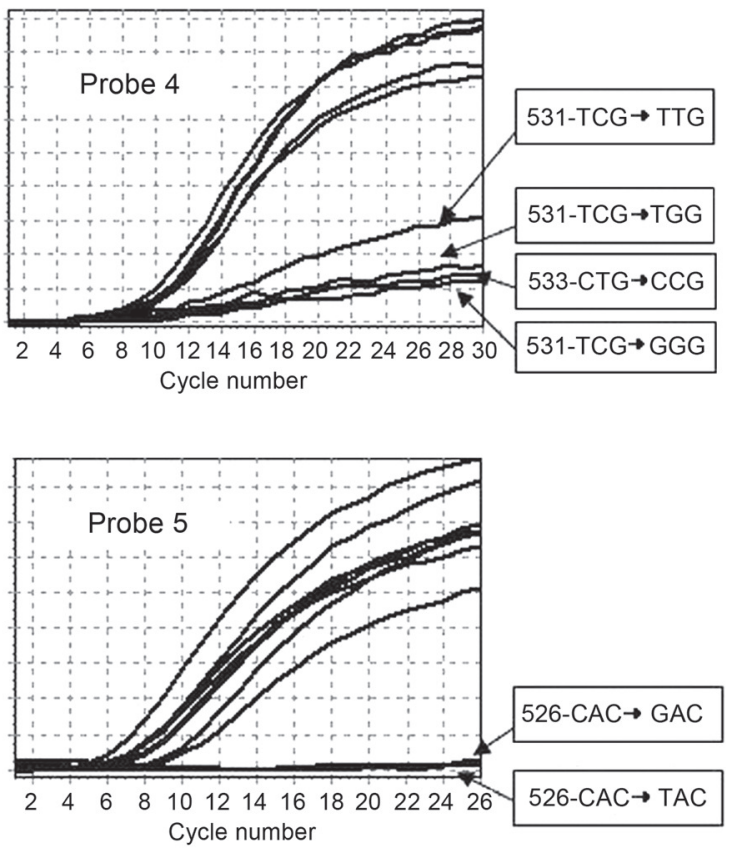

Fig. 4. Detection of point mutations in the rpoB-RRDR by real time PCR.

Shown are examples of real time PCR reactions for the detection of point mutations in the rifampin resistance determining region of the $r p o B$ gene (rpoB-RRDR) of different M. tuberculosis isolates. Each panel shows real-time PCR amplification curves using the MGB-probe indicated at the top (rpoB-probes 1, 2, 4 or 5, see Material \& Methods and Table II). Each curve corresponds to one M. tuberculosis isolate and one MGB-probe. Curves corresponding to isolates bearing mutations in the rpoB-RRDR are indicated by arrows with the type of mutation boxed. Such "mutant" curves appear clearly flat, with little or no fluorescence increase with increasing cycle number, compared to isolates with wild type sequences (which always show curves with a typical exponential, sigmoid shape). 

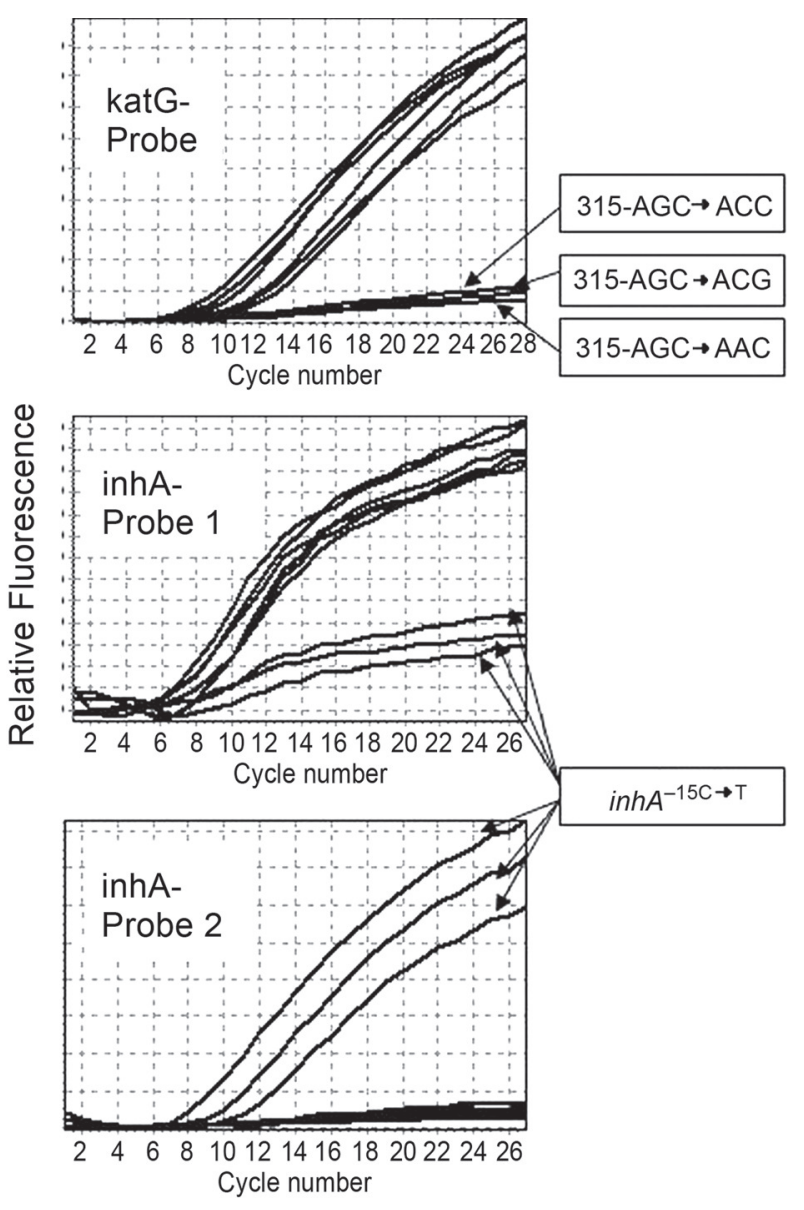

Fig. 5. Detection of point mutations in the $k a t G^{\text {codon315 }}$ and $i n h A^{-15}$ by real time PCR.

Shown are examples of real time PCR reactions for the detection of point mutations in the $k a t G^{\text {codon315 }}$ and inh $A^{-15}$ of different $M$. tuberculosis isolates. Each panel shows real-time PCR amplification curves using the MGB-probe indicated at the top (katG-Probe 1; inhA-probes 1 and 2; see Material and Methods and Table II). Each curve corresponds to one M.tuberculosis isolate and one MGB-probe. Curves corresponding to isolates bearing mutations in the $k a t G^{\text {codon315 }}$ or $i n h A^{-15}$ are indicated by arrows with the type of mutation boxed. Such "mutant" curves appear clearly flat, with little or no fluorescence increase with increasing cycle number, compared to isolates with wild type sequences. Note that only the three isolates showing the presence of a mutation with inhA-probel (matching wild type sequence, indicated by arrows) gave an amplification signal with inhA-probe2 (matching mutant sequence $i n h A^{-15 C \rightarrow T}$ ), demonstrating that these three isolates harbor the mutation $i n h A^{-15 C \rightarrow T}$ and are presumably INH resistant.

prediction of $M$. tuberculosis resistance to RIF and INH, we evaluated a real-time PCR method for the detection of point mutations in the rpoB-RRDR, $k a t G^{\text {codon315 }}$ and $i n h A^{-15}$. For each of the 160 clinical M. tuberculosis isolates studied, genomic DNA was isolated from bacterial culture and a triplex-PCR reaction was set up in order to amplify in the same tube three DNA fragments containing the three above mentioned targets (Fig. 3).

PCR products were diluted 1 to 50 and used as templates for second-round real-time PCR amplifications (8 tubes) in the presence of 8 different MGB-probes (Table II). Each tube contained one MGB-probe covering one target region (see Material \& Methods). In the case of full match between a probe and its target region (13-17bp), the corresponding amplification curve always showed a typical sigmoid (exponential) shape (Fig. 4). In contrast, the presence of a mismatch (point mutation) in the target region rendered the corresponding amplification curve clearly flat, with little or no fluorescence increase with increasing cycle number (Fig. 4). Using these MGB-probes, we were able to detect the presence of a point mutation in all M. tuberculosis isolates bearing a mutation in the rpoB-RRDR (62 isolates) and/or in $k a t G^{\text {codon315 }}$ (30 isolates). No mutations were detected in $r p o B$-RRDR or in $k a t G^{\text {codon315 }}$ of any $\mathrm{RIF}^{\mathrm{s}}$ or INH $\mathrm{IN}^{\mathrm{s}}$ isolate, respectively.

We were able to detect a point mutation at position -15 of the promoter of the InhA gene in 23 (32\%) $\mathrm{INH}^{\mathrm{r}}$ M. tuberculosis isolates. All of these isolates were $\mathrm{INH}^{\mathrm{r}}$. We were also able to identify all these 23 mutations as $i n h A^{-15 C \rightarrow T}$, since a MGB-probe matching $100 \%$ this mutation gave normal (exponential) amplification curves for all these 23 mutant isolates. As shown in Fig. 5, only isolates showing the presence of a mutation with inhA-probel (matching wild type sequence) gave fluorescence signal with inhA-probe2 (matching mutant sequence inh $A^{-15 \mathrm{C} \rightarrow \mathrm{T}}$ ). These results indicate that the probes used in this study can identify mutations in the target sequences with high accuracy.

\section{Discussion}

This is the first study from Syria that describes mutations in genes conferring rifampicin and isoniazid resistance in $M$. tuberculosis isolates. The high rate of MDR (38\%) found among the studied isolates is due to the fact that about $70 \%$ of TB patients included in this study had a history of failing chemotherapy and were likely to be infected with an MDR M. tuberculosis strain. Our aim was to characterize mutations causing MDR TB in Syria and to evaluate molecular methods to detect such mutations and rapidly predict drug resistance.

Similar to many other studies, RIF resistant M. tuberculosis isolates from Syria are frequently associated with mutations in $r p o B$ codons 516, 526 and 531. This finding is consistent with previous reports in which amino acid substitutions within codons 516, 526, and 531 have been associated with high-level rifampicin resistance in M. tuberculosis (Ohno et al., 1996). However, the most frequent mutation was Ser531Leu (56.5\%), which is in concordance with the high mutation rate of this codon in China (59.2\%) (Jiao et al., 2007), India (54.5\%) (Mani et al., 2001), Italy (56.7\%) (Pozzi et al., 1999), Turkey (56.7\%) (Cavusoglu et al., 2002) and most other countries. The high frequency of the Ser531Leu mutation is explained by the fact that it has no fitness cost to the mutant as compared to rifampicin-susceptible 
isolates (Gagneux, 2009). All other identified amino acid alterations leading to RIF resistance were previously described by other groups with two exceptions, Asp516Thr and Ser531Gly, which represent new mutations in the rpoB-RRDR described for the first time in association with RIF resistance. Only one mutation (Ile572Phe) was found outside the RRDR in this work. It is noteworthy that Ile572 is located inside the rifampicin binding pocket of the RNA-polymerase $\beta$-subunit spatial structure, very close to the Ser531 residue, where most RIF resistance mutations occur (Ederth et al., 2006). Therefore, alteration of Ile572 likely abolishes binding of rifampicin to the enzyme and causes RIF resistance without affecting enzyme essential functions. Six (8.7\%) Rifr isolates had no mutations in the region sequenced. This may be due to a mutation outside the sequenced region or to an entirely different mechanism of rifampicin resistance (Heep et al., 2001; Herrera et al., 2003).

Prevalence of mutations in the kat $G$ gene among $\operatorname{Inh}^{\mathrm{r}} M$. tuberculosis isolates found in this study (41.6\%) lies within the international range (40-95\%) and is comparable to most previous reports. A large number of different mutations in the kat $G$ gene have been described thus far. However, the Ser315Thr mutation is found most often, occurring in approximately $40 \%$ of all isoniazid-resistant strains (Hazbón et al., 2006; Silva et al., 2003; Ramaswamy and Musser, 1998; Zhang and Telenti, 2000). We found almost exclusively the Ser315Thr substitution among this set of diverse INH resistant isolates. This highlights the selective advantage conferred by the Ser315Thr mutation, which provides enough catalase-peroxidase activity to protect the cell from oxidative stress while reducing the conversion of the INH prodrug to its active form by KatG (Rouse et al., 1996; van Soolingen et al., 2000; Wei et al., 2003).

The active form of INH is thought to inactivate the fatty-acid enoyl-acyl carrier protein reductase (InhA) involved in synthesis of mycolic acids. It is proposed that the $-15 \mathrm{C} \rightarrow \mathrm{T}$ mutation in the ribosome binding site of the promoter of the mabA-inhA operon causes over-expression of InhA, thus providing excess active enzyme and leading to isoniazid resistance in mutant strains (Zhang and Telenti, 2000; Slayden and Barry, 2000). Of $72 \mathrm{INH}^{\mathrm{r}}$ isolates included in our study, $23(32 \%)$ harbored the inh $A^{-15 \mathrm{C} \rightarrow \mathrm{T}}$ mutation. This rate is higher than values found in most other countries (15\% in eastern China, $19.2 \%$ in Lithuania, $23.6 \%$ in Spain, and 27.2\% in England) (Zhang et al., 2005; Bakonyte et al., 2003; Herrera-León et al., 2003; Baker et al., 2005, respectively). The majority (20/23) of $\mathrm{Inh}^{\mathrm{r}}$ isolates harboring the inh $A^{-15 \mathrm{C} \rightarrow \mathrm{T}}$ mutation had no mutation in kat $G$ codon 315 , which emphasizes the great importance of testing the $i n h A^{-15 \mathrm{C} \rightarrow \mathrm{T}}$ mutation all along with $k a t G$ codon 315.
22 (30.5\%) Inh ${ }^{\mathrm{r}}$ isolates had no mutations either in the region sequenced of the $k a t G$ gene or in position -15 of the inhA promoter. This may be due to mutations outside the sequenced region of the $k a t G$ gene or mutations in the inhA structural region. Such mutations can account for up to $30 \%$ of INH resistance (Fressatti Cardoso et al., 2004).

Rapid assessment of drug sensitivity is crucial for clinical management of patients infected with $M$. tuberculosis. Our aim was to test and validate a rapid and cost-effective real-time PCR assay for detection of RIF and INH resistance of bacterial cultures using 3'-Minor groove binder-DNA probes (Wada et al., 2004). For optimal detection of point mutations, probes should be as short as possible, because mismatch of a single nucleotide then results in a greater destabilizing effect on probe-amplicon binding and enhances the discriminatory power. In addition, short probes are less influenced by the heterogeneity of the target sequence surrounding the mutation. An MGB probe consists of a 13 to 15-bplong oligonucleotide that carries both a fluorescent dye at its 5 ' end and a nonfluorescent quencher and a minor groove binder at its 3' end. MGB probes have the advantage of an MGB polycyclic chemical group that binds nonspecifically to double-stranded DNA (generated by the hybridization of the probe to its target DNA region). The presence of the MGB-moiety increases the melting temperature of the probe-amplicon binding and allows relatively short probes to have a melting temperature of $\sim 60^{\circ} \mathrm{C}$ (Kutyavin et al., 2000). Therefore, the MGBmoiety allows the probes to be shorter and thus more discriminatory.

Using such short MGB-probes in real-time PCR, we were able to detect the presence of all mutations found by DNA sequencing of the rpoB-RRDR or in codon 315 of the kat $G$ gene, in addition to the detection of the inh $A^{-15 C \rightarrow \mathrm{T}}$ mutation in 23 isolates. All these mutant isolates could be correctly predicted as $\mathrm{Rif}^{\mathrm{r}}$ or $\mathrm{Inh}^{\mathrm{r}}$ (positive predictive value $=100 \%$ ). In addition, none of Rif ${ }^{s}$ or Inhs isolates tested positive in real-time PCR, indicating that false positivity is very rare in this system. Nevertheless, for each positive result in real-time PCR, the presence of a mutation should be confirmed by repeating the PCR reaction using the corresponding probe in order to minimize false positivity.

Out of 69 Rif $^{\mathrm{r}}$ bacterial M.tuberculosis isolates, $62(90 \%)$ were correctly predicted as Rifr, and out of $72 \mathrm{Inh}^{\mathrm{r}}$ isolates, 50 (69.4\%) were correctly predicted as Inh $^{\mathrm{r}}$ by real-time PCR. Therefore, the sensitivity of this assay in identifying Rif ${ }^{\mathrm{r}}$ and $\mathrm{Inh}^{\mathrm{r}}$ isolates is $90 \%$ and $69.4 \%$, respectively. It is clear that this assay does not detect mutations occurring outside the target regions (such as the $r p o B$ Ile572Phe mutation) covered by the probe set, which results in a rate of false negativity of $10 \%$ and $30.6 \%$ in detecting Rif ${ }^{\mathrm{r}}$ or $\mathrm{Inh}^{\mathrm{r}}$ isolates, respec- 
tively. This limitation highlights the importance of bacteriological susceptibility testing methods in achieving comprehensive identification of resistance among clinical isolates. Sensitivity values are valid for gDNA isolated from bacterial colonies grown on solid medium, and they could be lower if this real-time PCR assay was used to amplify gDNA directly isolated from sputum, due to the very low number of $M$. tuberculosis bacilli in clinical samples. Nevertheless, real-time PCR on bacterial colonies reduces RIF/INH resistance testing time from several weeks using conventional bacterial culture to only 1 day.

In conclusion, the real-time PCR assay is able to detect most of Rif $^{\mathrm{r}}$ and $\mathrm{Inh}^{\mathrm{r}}$ isolates. The method is rapid, it requires simple equipment, and the results are easy to interpret. This low-cost test represents a benefit for TB patients and can be used as first line test for rapid detection of MDR isolates in developing countries like Syria as a complement to the phenotypic tests.

\section{Acknowledgments}

We thank Dr. Ibrahim Othman (General Director of the AECS), Dr. Ouael Alhalaki (Minister of Health), Dr. Mohammad M. Nemeh (head of Department of Radiation Medicine in the AECS), Dr. Roula Hammoud (Director of the Directorate of the Public Health of Syria), and Dr. Kinaz Alshek (Director of National TB Program in Syria), for their support to complete this work.

\section{Literature}

Baker L.V., T.J. Brown, O. Maxwell, A.L. Gibson, Z. Fang, M.D. Yates and F.A. Drobniewski. 2005. Molecular analysis of isoniazid-resistant Mycobacterium tuberculosis isolates from England and Wales reveals the phylogenetic significance of the ahpC-46A polymorphism. Antimicrob. Agents Chemother. 49: 41455-1464.

Bakonyte D., A. Baranauskaite, J. Cicenaite, A. Sosnovskaja and P. Stakenas. 2003. Molecular characterization of isoniazid-resistant Mycobacterium tuberculosis clinical isolates in Lithuania. Antimicrob. Agents Chemother. 47: 2009-2011.

Bobadilla-del-Valle M., A. Ponce-de-Leon, C. Arenas-Huertero, G. Vargas-Alarcon, M. Kato-Maeda, P.M. Small, P. Couary, G.M. Ruiz-Palacios and J. Sifuentes-Osornio. 2001. rpoB gene mutations in rifampin-resistant Mycobacterium tuberculosis identified by polymerase chain reaction single-stranded conformational polymorphism. Emer. Infect. Dis. 7: 1010-1013.

Cavusoglu C., S. Hilmioglu, S. Guneri and A. Bilgic. 2002. Characterization of $r p o B$ mutations in rifampin-resistant clinical isolates of Mycobacterium tuberculosis from Turkey by DNA sequencing and line probe assay. J. Clin. Microbiol. 40: 4435-4438.

Dye C. 2006. Global epidemiology of tuberculosis. Lancet 367: 938-940.

Ederth J., R. Mooney, L. Isaksson and R. Landick. 2006. Functional interplay between the Jaw Domain of bacterial RNA polymerase and allele-specific residues in the product RNA-binding pocket. J. Mol. Biol. 356: 1163-1179.

Fressatti Cardoso R., R. Cooksey, G. Morlock, P. Barco, L. Cecon, F. Forestiero, C.Q.F. Leite, D.N. Sato, M. de Lourdes Shikama, E.M. Mamizuka and others. 2004. Screening and characterization of mutations in isoniazid-resistant Mycobacterium tuberculo- sis isolates obtained in Brazil. Antimicrob. Agents Chemother. 48: 3373-3381.

Gagneux S. 2009. Fitness cost of drug resistance in Mycobacterium tuberculosis. Clin. Microbiol. Infect. 15:66-68.

García de Viedma D. 2003. Rapid detection of resistance in Mycobacterium tuberculosis: a review discussing molecular approaches. Clin. Microbiol. Infect. 9: 349-359.

Hazbón M.H., M. Brimacombe, M. Bobadilla del Valle, M. Cavatore, M. Inírida Guerrero, M. Varma-Basil, H. Billman-Jacobe, C. Lavender, J. Fyfe, L. Garcia-Garcia and others. 2006. Population genetics study of isoniazid resistance mutations and evolution of multidrug resistant Mycobacterium tuberculosis. Antimicrob. Agents Chemother. 50: 2640-2649.

Heep M., B. Brandstatter, U. Rieger, N. Lehn, E. Richter, S. RuschGerdes and S. Niemann. 2001. Frequency of $r p o B$ mutations inside and outside the cluster I region in rifampin-resistant clinical Mycobacterium tuberculosis isolates. J. Clin. Microbiol. 39: 107-110.

Herrera L., S. Jimenez, A. Valcerde, M.A. Garcia-Aranda and J.A. Saez-Nieto. 2003. Molecular analysis of rifampicin-resistant Mycobacterium tuberculosis isolated in Spain (1996-2001). Description of new mutations in the $r p o B$ gene and review of the literature. Int. J. Antimicrob. Agents. 21: 403-408.

Jiao W., I. Mokrousov, G. Sun, M. Li, J. Liu, O. Narvskaya and A. Shen. 2007. Molecular characteristics of rifampin and isoniazid resistant Mycobacterium tuberculosis strains from Beijing, China. Chin. Med. J. 120: 814-819.

Kutyavin I.V., I.A. Afonina, A. Mills, V.V. Gorn, E.A. Lukhtanov, E.S. Belousov, M.J. Singer, D.K. Walburger, S.G. Lokhov, A.A. Gall and others. 2000. 3'-Minor groove binder-DNA probes increase sequence specificity at PCR extension temperatures. Nucleic Acids Res. 28: 655-661.

Mani C., N. Selvakumar, S. Narayanan and P.R. Narayanan. 2001. Mutations in the rpoB gene of multidrug-resistant Mycobacterium tuberculosis clinical isolates from India. J. Clin. Microbiol. 39: 2987-2990.

McCammon M., J. Gillette, P. Thomas, V. Ramaswamy, A. Graviss, N. Kreiswirth, J. Vijg and N. Quitugua. 2005. Detection of $r p o B$ mutations associated with rifampin resistance in Mycobacterium tuberculosis using denaturing gradient gel electrophoresis. Antimicrob. Agents Chemother. 49: 2200-2209.

Narvaiz de Kantor I., S.J. Kim, T. Frieden, A. Laszlo, F. Luelmo, P.Y. Norval, H. Rieder, P. Valenzuela and K. Weyer. 1998. LABORATORY SERVICES IN TUBERCULOSIS CONTROL, For the Global Tuberculosis Programme, World Health Organization, Geneva, Switzerland.

Ohno H., H. Koga, S. Kohno, T. Tashiro, and K. Hara. 1996. Relationship between rifampin MICs and rpoB mutations of $M y c o-$ bacterium tuberculosis strains isolated in Japan. Antimicrob. Agents Chemother. 40: 1053-1056.

Pozzi G., M. Meloni, E. Iona, G. Orro, O.F. Thorensen, M.L. Ricci, M.R. Oggioni, L. Fattorini and G. Orefici. 1999. rpoB mutations in multidrug resistant strains of Mycobacterium tuberculosis isolated in Italy. J. Clin. Microbiol. 37:1197-1199.

Ramaswamy S.V. and J.M. Musser. 1998. Molecular genetic basis of antimicrobial agent resistance in Mycobacterium tuberculosis: 1998 update. Tuberc. Lung. Dis. 79:3-29.

Ramaswamy S.V., R. Reich, S.J. Dou, L. Jasperse, X. Pan, A. Wanger, T. Quitugua and E.A. Graviss. 2003. Single nucleotide polymorphisms in genes associated with isoniazid resistance in Mycobacterium tuberculosis. Antimicrob. Agents Chemother. 47: 1241-1250.

Rouse, D. A., J. A. DeVito, Z. Li, H. Byer, and S. L. Morris. 1996. Site directed mutagenesis of the kat $G$ gene of Mycobacterium tuberculosis: effects on catalase-peroxidase activities and isoniazid resistance. Mol. Microbiol. 22: 583-592. 
Silva M.S., S.G. Senna, M.O. Ribeiro, A.R. Valim, M.A. Telles, A. Kritski, G.P. Morlock, R.C. Cooksey, A. Zaha and M.L. Rossetti. 2003. Mutations in katG, inhA, and ahpC genes of Brazilian isoniazid-resistant isolates of Mycobacterium tuberculosis. J. Clin. Microbiol. 41: 4471-4474.

Slayden R.A. and C.E. Barry 3rd. 2000. The genetics and biochemistry of isoniazid resistance in Mycobacterium tuberculosis. Microbes Infect. 2: 659-669.

Telenti A., N. Honore, C. Bernasconi, J. March, A. Ortega, B. Heym, H.E. Takiff and S.T. Cole. 1997. Genotypic assessment of isoniazid and rifampin resistance in Mycobacterium tuberculosis: a blind study at reference laboratory level. J. Clin. Microbiol. 35: 719-723.

van Soolingen D., P.E. de Haas, H.R. van Doorn, E. Kuijper, H. Rinder and M.W. Borgdorff. 2000. Mutations at amino acid position 315 of the kat $G$ gene are associated with high-level resistance to isoniazid, other drug resistance, and successful transmission of Mycobacterium tuberculosis in the Netherlands. J. Infect. Dis. 182: 1788-1790.

Wada T., S. Maeda, A. Tamaru, S. Imai, A. Hase and K. Kobayashi. 2004. Dual-probe assay for rapid detection of drug-resistant Mycobacterium tuberculosis by real-time PCR. J. Clin. Microbiol. 42: 5277-5285.
Wei C.J., B. Lei, J.M. Musser and S.C. Tu. 2003. Isoniazid activation defects in recombinant Mycobacterium tuberculosis catalaseperoxidase (KatG) mutants evident in InhA inhibitor production. Antimicrob. Agents Chemother. 47: 670-675.

World Health Organization. 2005. Global tuberculosis control: surveillance, planning, financing. WHO report 2005. WHO/HTM/ TB/2005.349. Geneva.

World Health Organization. 2010. Multidrug and extensively drug resistant TB (M/XDR-TB): 2010 global report on surveillance and response. WHO/HTM/TB/2010.3. Geneva, Switzerland.

Yuen L.K.W., D. Leslie and P.J. Coloe. 1999. Bacteriological and molecular analysis of rifampin-resistant Mycobacterium tuberculosis strains isolated in Australia. J. Clin. Microbiol. 37: 3844-3850.

Zhang Y. and A. Telenti. 2000. Genetics of drug resistance in Mycobacterium tuberculosis, p. 235-254. In Hatfull F.F and Jacobs W.R Jr. (ed.), Molecular genetics of mycobacteria. ASM Press, Washington, D.C.

Zhang M., J. Yue, Y.P. Yang, H.M. Zhang, J.Q. Lei, R.L. Jin, X.L. Zhang and H.H. Wang. 2005. Detection of mutations associated with isoniazid resistance in Mycobacterium tuberculosis isolates from China. J. Clin. Microbiol. 43: 5477-5482. 